\title{
Selection of reference genes for quantitative RT-PCR (RT- qPCR) analysis on rat endocrine tissues under physiological and toxicological conditions
}

Terje Svingen, Heidi Letting, Niels Hadrup, Ulla Hass, Anne Marie Vinggaard

In biological research the analysis of gene expression levels in cells and tissues can be a powerful tool to gain insights into biological processes. For this, quantitative RT-PCR (RTqPCR) is a popular method that often involve the use of constitutively expressed endogenous reference (or 'housekeeping') gene for normalization of data. Thus, it is essential to use reference genes that have been verified to be stably expressed within the specific experimental setting. Here, we have analysed the expression stability of 12 commonly used reference genes (Actb, B2m, Gapdh, Hprt, Pgk1, Rn18s, Rpl13a, Rps18, Rps29, Sdha, Tbp and Ubc) across several juvenile and adult rat tissues (liver, adrenal, prostate, fat pad, testis and ovaries), both under normal conditions and following in utero exposure to various chemicals. Employing NormFinder and BestKeeper softwares, we found Hprt and Sdha to be amongst the most stable genes across normal and manipulated tissues, with several others also being suitable for most tissues. Tbp and B2m displayed highest variability in transcript levels between tissues and developmental stages. It was also observed that the reference genes were most unstable in liver and testis following toxicological exposure. For future studies, we propose the use of more than one verified reference gene and the continuous monitoring of their suitability under various experimental conditions, including toxicological studies, based on changes in threshold (Ct) values from cDNA samples having been reverse-transcribed from a constant input concentration of RNA. 
5 Selection of reference genes for quantitative RT-PCR (RT6 qPCR) analysis on rat endocrine tissues under physiological and

7 toxicological condition

8

9 Terje Svingen*, Heidi Letting, Niels Hadrup, Ulla Hass and Anne Marie Vinggaard

10

11 Division of Toxicology and Risk Assessment, National Food Institute, Technical University of

12 Denmark, Søborg DK-2860, Denmark

13

14

15

$16 *$ Author for correspondence:

17 Tel: $(+45) 35887532$

18 Email:tesv@food.dtu.dk

19

20

21

22

23

24

25

26

27

28

29 


\section{INTRODUCTION}

34 Despite the advent of high-throughput methods such as RNA-sequencing to measure transcript

35 abundance in cells and tissues, quantitative RT-PCR (RT-qPCR) remains the method of choice for

36 many, particularly when only a selected number of genes are to be analysed. The RT-qPCR

37 methodology has itself improved greatly over the past two decades with advances to most parameters,

38 including reaction chemistries and platform technologies. However, it remains critically dependent

39 upon a number of technical parameters that can significantly impact on the end results (Nolan et al.

40 2006). Among the most critical aspects is correct normalisation, both to control for experimental errors

41 and adjust for inter-sample variations.

43 There are many strategies for normalising RT-qPCR data (Huggett et al. 2005) and the most frequently

44 used is normalisation with an endogenous reference gene that is stably expressed across all the

45 samples. This approach using the comparative $\mathrm{Ct}$ (or $2^{-\Delta \mathrm{Ct}}$ ) method (Schmittgen \& Livak 2008) is

46 sound, but rests on the assumption that transcript abundance of the reference gene is the same in all

47 cells, under all conditions. A growing body of evidence has clearly shown this not to be the case and

48 that 'stably expressed' reference genes must be determined for each cell/tissue type during different

49 stages of development and under all experimental conditions (reviewed by Huggett et al. 2005; Kozera

50 \& Rapacz 2013). This can quickly become a Herculean task and likely a major reason why it remains

51 so frequently overlooked. In a recent report, Piller and co-workers scrutinized recent publications in

52 their field of research - rat spared nerve injury model of neuropathic pain - for evidence-based use of 
53 reference genes in RT-qPCR experiments and found that only 2 out of 26 peer-reviewed articles

54 referred to proper validation for their reference genes (Piller et al. 2013).

56 Over the years, there has been a steady increase in studies reporting on the suitability of various

57 reference genes in rat tissues under specific experimental conditions. The liver has perhaps received

58 most attention, but also include tissues such as the intestine, brain and other neuronal tissues, muscle,

59 spleen, mammary gland, lung, and ovary (Cabiati et al. 2012; Das et al. 2013; DuBois et al. 2013; Hvid

60 et al. 2011; Langnaese et al. 2008; Lardizábal et al. 2012; Martínez-Beamonte et al. 2011; Pohjanvirta

61 et al. 2006; Taki et al. 2014; Verma \& Shapiro 2006). What is striking about these studies, and others,

62 is the large overlap in genes that have been analysed, but relatively small overlap in what genes are

63 deemed expressed stable enough to be used for normalization purposes. The most commonly used

64 genes are Actb, Gapdh, Rn18s (18S rRNA), Hprt1 and B2m, perhaps because they are historical carry-

65 overs from other semi-quantitative methods and not because they have been empirically tested. In fact,

66 these genes have often been shown not to be particularly stable under various experimental conditions,

67 but nevertheless continue to be the most frequently used.

68

69 In animal-based toxicological studies, the rat has become a tractable model and gene expression

70 profiling is often performed. Studies also often include an array of different tissues, perhaps from

71 various stages of development. Thus, these tissues vary not only in cell composition, but also by

72 experimental manipulations, and the variability of tissues may potentially extend to expression levels

73 of endogenous reference genes. It is now clear that commonly used reference genes such as Actb,

74 Gapdh, Ubc and Rn18s can vary considerably depending on tissue types, developmental stage, sex,

75 pathology, and experimental conditions (Das et al. 2013; Kim et al. 2011; Martínez-Beamonte et al.

76 2011; Pohjanvirta et al. 2006; Ruedrich et al. 2013; Swijsen et al. 2012). Thus, more emphasis should 
77 be given to proper validation of suitable reference genes to ensure accurate, reproducible and

78 biologically relevant gene expression data. Here, we have addressed this issue by analysing the

79 expression stability of 12 putative endogenous reference genes in rat tissues, both from unexposed

80 controls and from rats having been exposed to chemicals during development.

81

82

83

84

85

86

87

88

89

90

91

92

93

94

95

96

97

98

99

100

\section{MATERIALS AND METHODS}

\section{Animals}

Experimental protocols and use of animals were approved by the Danish Animal Experiments Inspectorate (Permit No. 2012-15-2934-00089 C4) and overseen by the Animal Welfare Committee of the National Food Institute, Technical University of Denmark. All tissue samples used in this study were from Wistar rats, either control rats, or rats having been exposed to a mixture of chemicals as described previously (Christiansen et al. 2012; Hadrup et al. 2015). In short, one group was exposed perinatally to a mixture of 13 known endocrine disrupting compounds at a dose estimated at 450 -times higher than that of human exposure, designated Mix450 (Christiansen et al. 2012), with juvenile tissue samples collected on postnatal days (P): livers on P13; testis, prostate and adrenal on P16; ovaries on P17; and adult tissues after P55. A second and third group of juvenile male rats was exposed to 5 $\mathrm{mg} / \mathrm{kg}$ perfluoronanoic acid (PFNA) and $5 \mathrm{mg} / \mathrm{kg}$ PFNA in addition to a mixture of 14 chemicals (PFNA/mix), respectively (Hadrup et al. 2015), and tissues were collected from adult rats.

\section{RNA extraction, cDNA synthesis and quantitative RT-PCR (RT-qPCR)}

Total RNA was extracted from homogenized rat tissues using the RNeasy Mini kit (Qiagen) including on-column DNaseI treatment. RNA purity and quantity were measured by nano-drop 
101 spectrophotometry, and $500 \mathrm{ng}$ total RNA (A260/280 ratio of $1.95 \pm 0.1$ ) used to synthesise cDNA in

102 the presence of $6 \mu \mathrm{M}$ Random Primer mix (New England Biolabs) using the Omniscript kit (Qiagen) in

$10320 \mu 1$ reactions as per manufacturer's instructions. cDNA samples were diluted 1:20 and $3 \mu 1$ used in

$10411 \mu 1$ RT-qPCR reactions together with $5 \mu 1$ TaqMan Fast Universal Master mix (Life Technologies),

$1050.5 \mu 1$ TaqMan Gene Expression Assay (Life Technologies) and $2.5 \mu 1$ sterile water. RT-qPCR assays

106 were run in duplicates on a 7900HT Fast Real-Time PCR System (Applied Biosystems) in 384-well

107 plates over 45 cycles of $95^{\circ} \mathrm{C}$ for $1 \mathrm{~s}$ and $60^{\circ} \mathrm{C}$ for $20 \mathrm{~s}$ in a two-step thermal cycle preceded by an

108 initiation step of $95^{\circ} \mathrm{C}$ for $20 \mathrm{~s}$. Accompanying software was used for the acquisition of threshold cycle

109 (Ct) values. Individual TaqMan Gene Assays with verified amplification efficiencies were purchased

110 from Life Technologies and their corresponding product numbers are listed in Table 1. The Rn18s

111 assay was designed previously (Boberg et al. 2013), with forward and reverse primers run at $900 \mathrm{nM}$

112 and TaqMan probe at $250 \mathrm{nM}$ final concentrations. Amplification efficiency of the $R n 18 s$ assay was

113 calculated to $97 \%$ by standard curve analysis on 6 serial 10 -fold dilutions in triplicates.

\section{Analytical methods}

116 RT-qPCR Ct values were acquired using the Applied Biosystems 7900HT Fast Real-Time PCR System

117 software and relative gene expression calculated by the $2^{(-\Delta \mathrm{Ct})}$ method (Applied Biosystems Research

118 Bulletin No. 2 P/N 4303859). Expression stability of putative reference genes was estimated using the

119 BestKeeper (Technical University of Munich, Germany) and NormFinder (Aarhus University Hospital,

120 Denmark) softwares.

122 BestKeeper make use of unconverted Ct values to perform parametric tests on normally distributed

123 expression levels. It estimates the geometric mean of $\mathrm{Ct}$ values, determines the coefficient of variance

124 (CV) for each gene, and calculates a Pearson's coefficient of correlation ( $r$ ). Standard deviation (SD) 
125 calculations are performed to create a weighted index of most suitable normalizing genes across

126 selected biological samples and exclude genes that are not stably expressed (Pfaffl et al. 2004).

127 NormFinder uses $\mathrm{Ct}$ values transformed to a linear scale to estimate expression stability (S), combining

128 intra- and inter-group variations for each reference gene. The algorithm takes into account biological

129 heterogeneity and avoids selection bias caused by co-regulation of genes (Andersen et al. 2004).

130

131

\section{RESULTS}

133

134 Before testing the expression stability of the 12 endogenous reference genes, all cDNA samples were

135 normalised at the RNA level. Following RT-qPCR cycling, the raw mean Ct values of duplicate

136 reactions were acquired, representing raw expression data. Ct values were used for statistical analyses.

138 From juvenile control rats, four biological replicates each of liver, fat pad, adrenal, prostate, testis and 139 ovary tissues were analysed and the mean Ct values determined (Table 2). There was low inter-assay

140 variation within the tissue types, with most standard deviation (SD) values being $<0.5$ and the highest

141 0.76. A larger variation was evident between tissue types, with SD values across all the 24 tissue

142 samples being $>0.5$ and that of Actb, Pgkl, Rpl13a, and Tbp exceeding 1.0. The expression range of the 143 individual reference genes are represented as box plots in Fig. 1A.

145 From adult control rats, four biological replicates each of liver, fat pad, prostate and testis tissues were 146 analysed and the mean Ct values determined (Table 3). Again, there was low inter-assay variation

147 within tissue types for most of the reference genes, with most SD values being $<0.5$. One exception

148 was $R n 18 s$ where SD values were $>1.5$ in liver and testis, and 0.94 in prostate. Between different 
149 tissues, the variation in $\mathrm{Ct}$ values was larger. Across all the 16 tissue samples (4 tissue types) the SD

150 was $>0.5$ for all reference genes, with $B 2 m$, Gapdh, Rn $18 s, R p s 18$ and Tbp exceeding 1.0. Notably, Tbp

151 displayed a significantly lower $\mathrm{Ct}$ value in adult testis $(\mathrm{Ct}=24.8)$ than in any other adult or juvenile

152 tissues $(\mathrm{Ct}=28.2-32.7)$. The expression range of the individual reference genes across adult tissues are

153 given as box plots in Fig. 1B.

154

155 Reference genes would be expected to display most stable transcript abundance between samples of the 156 same tissues and organs and within similar developmental stages. The greatest variations to expression 157 levels would be expected between different tissue types, at different developmental stages, but also if 158 they have been affected by external factors. Here, we included RT-qPCR analyses of tissues from rats

159 having been exposed to mixtures of chemical compounds. These tissue samples correlated with the 160 control tissues above. The first group comprised juvenile ovaries and prostate, as well as adult prostate 161 tissues obtained from rats having been exposed peri- and postnatally to Mix450 (Table 4). Some 162 smaller variations in $\mathrm{Ct}$ values were observed between tissues from those of the control animals 163 (Tables 2 and 3 ), but did not exceed 0.5 cycles. The second group comprised adult liver, fat pad and 164 testis tissues obtained from male rats having been exposed postnatally to either PFNA or PFNA/mix 165 (Table 5). Here, greater variability of Ct values compared to tissues from control animals (Table 3) was 166 evident. In the liver, the $\mathrm{Ct}$ values from several genes varied by more than $1.0 \mathrm{cycle}$, including Gapdh, 167 Hprt, Pgkl, Rps29, Rpl13a and Rps18, the latter two with as much as 2.6 and 3.1 cycles, respectively.

168 In the fat pad the difference in expression was far less, with only Gapdh in PFNA-exposed rats 169 exceeding 1.0 cycle difference relative to control. In the testis, most changes to $\mathrm{Ct}$ values in exposed

170 animals versus control was less than 1.0 cycle, but with Gapdh varying by 1.5 cycles in PFNA/mix and 171 Rn18s as much as 2.2 cycles in the PFNA group. 
173 To assess relative expression stability across different biological samples, we analysed the Ct outputs 174 with NormFinder (Andersen et al. 2004). First, raw Ct values were converted to linear scale by the 2($175 \Delta \mathrm{Ct})$ method using the geometric mean of Hprt, Pgk1, Rpl13a, Rps18, Rps29, Sdha and Ubc based on 176 initial determination of coefficient of variance (CV) across the biological replicates (data not shown).

177 Based on converted Ct values, the software calculates a stability value (S) for each gene across the 178 selected biological replicates. First we assessed expression stability across control tissues, which 179 included the 40 biological replicates listed in Tables 2 and 3 (Fig. 2A). Here, Hprt and Sdha were 180 ranked as the most stable, whereas $T b p$ and $B 2 m$ were deemed least stable. NormFinder recommends 181 an upper S-value of 0.5 for genes to be assessed as relatively stable. Only Hprt and Sdha had an S-

182 value $<0.5$, but $U b c, A c t b, R p l 13 a$ and $R p s 18$ were all close to 0.5 . A further 36 samples were included 183 in the NormFinder assessment, which included tissues from adult rats that had been exposed to 184 chemical mixtures during development (Fig. 2B). The most stably expressed genes Hprt and Sdha (as 185 determined above) appeared relatively unchanged in these tissues, whereas more unstably expressed 186 genes shifted to a significantly higher S-value. This was particularly evident for $T b p, B 2 m, G a p d h$ and

$187 R n 18$ s. NormFinder was also used to assess pairwise expression stabilities of the 12 reference genes 188 between juvenile rat tissues. Although it represents only a selection of possible pairing of tissues, it 189 illustrates that optimal reference genes can vary significantly between tissue types (Table 6).

191 Next, relative expression stability was assessed by the BestKeeper software (Pfaffl et al. 2004), which 192 defined genes that display a SD >1.0 as unstable. Based on the NormFinder output, we excluded Tbp 193 and $B 2 m$ from these analyses, only assessing the remaining 10 reference genes. The analyses were first 194 performed with the 40 control samples listed in Tables 2 and 3. Eight of the genes displayed a SD $<1.0$, 195 with the remaining two, $P g k 1$ and $A c t b$, SD $>1.0$ (Table 7). Rn18s displayed the lowest SD, but with $196 P=0.296$ it is not possible to conclude on stability. When including an additional 36 tissue samples 
197 from rats exposed to chemical mixtures (Tables 4 and 5), the stability ranking of the genes altered. 198 Again, eight genes had an SD $<1.0$, but $P g k l$ and Gapdh had an SD $>1.0$, thus excluding them as 199 suitable reference genes for these tissue samples (Table 7).

\section{DISCUSSION}

204 The use of a suitable reference when normalizing RT-qPCR data is essential to obtain data that truthfully represents relative transcript abundance of genes within cells and tissues. The most common strategy is to use endogenous reference genes, but unfortunately the chosen reference genes have often not been properly verified as being stably expressed across the samples being analysed. Here, we have analysed a panel of 12 commonly used reference genes across various tissues from juvenile and adult rats and recommend what reference genes to use for these tissues based on empirical data. Further

210 guidance on how to monitor and select suitable reference genes for future rat studies with variable 211 experimental parameters is given.

213 When looking at specific tissues, the relative expression levels of reference genes are normally quite 214 stable between biological samples. Significant variability in RNA transcript abundance is often first 215 encountered when comparing the same tissue type from different developmental stages, when 216 comparing different types of tissues, or when severe adverse effects are induced (Cabiati et al. 2012;

217 DuBois et al. 2013; Hvid et al. 2011; Kim et al. 2011; Martínez-Beamonte et al. 2011; Svingen et al. 218 2009). Here, we found several reference genes to be relatively stable across juvenile and adult rat 219 tissues, however none of the 12 genes showed variations $\mathrm{Ct}<1.0$ when assessed across all 10 different 220 biological groups. For example, Hprt, which generally showed the greatest stability across tissues, 
221 displayed lower expression levels (higher Ct) in liver than in any other tissue. Also Actb, Rpl13a, 222 Rps18 and Tbp showed a similar trend of being expressed at a lower level in liver than in other tissues.

223 Rn18s was generally stable across tissues with the exception of the fat pad where relative expression

224 typically was higher (lower Ct by approx. 2.0) than for other tissues, which could suggests that the

$225 \mathrm{rRNA} / \mathrm{mRNA}$ ration is skewed between these tissues. Another example is the higher expression of $T b p$

226 in juvenile testis and ovary, compared to other tissues and an even higher expression in adult testis (Ct

$227>5.0$ difference). Tbp has previously been shown to be a suitable reference gene in fetal mouse gonads,

228 as well as human fetal testis (O'Shaughnessy et al. 2011; Svingen et al. 2009), which highlights the

229 importance of not simply relying on data from one species (e.g. mouse) when selecting suitable

230 reference genes for another (e.g. rat).

231

232 An additional problem is encountered when normalizing gene expression in experimentally

233 manipulated tissues; in the context of this study, animals that had been exposed to a variety of

234 chemicals, often at toxicological dose levels. Experimental manipulations can adversely affect gene

235 expression levels in various tissues, including genes normally regarded as 'stable housekeeping genes'

236 (Das et al. 2013; DuBois et al. 2013; Martínez-Beamonte et al. 2011; Nair et al. 2014; Pohjanvirta et al.

237 2006; Santin et al. 2013; Silver et al. 2008; Taki et al. 2014). Here, we have also shown that the

238 expression of endogenous reference genes such as $T b p, B 2 m$ and Gapdh are affected in tissues having

239 been exposed to chemicals during development. Although most changes in relative transcript

240 abundance were less than one cycle $(\mathrm{Ct}<1.0)$, some tissues displayed higher variability following

241 chemical exposure. Not surprisingly the liver was most affected, with for instance Pgkl, Rpll3a and

242 Rps 18 shifting as much as $\mathrm{Ct}>1.5,>2.5$ and $>3.0$, respectively in animals having been exposed to high

243 PFNA levels with or without a background mix of chemicals (Table 3 versus 5). In numerical terms,

244 this could translate into a nearly 10 -fold difference in reported change in relative fold gene expression. 
245 As reported previously (Hadrup et al. 2015), the PFNA exposure was modelled on high-end human

246 relevant exposure and animals were affected to variable degree. For instance, the livers from exposed

247 rats displayed some hypertrophy and steatosis. Other organs did not show significant effects at a

248 macroscopic or histological level, but high doses resulted in decreased levels of systemic androgens

249 (testosterone) and increased aromatase expression in fatty tissues. There was also an observable

250 downregulation of steroidogenic genes in the testes from high-dosed rats, including StAR, Cyp 1 lal,

251 Cyp17al and Hsd17b1, suggestive of a decreased steroidogenic output.

253 Previous studies have reported on the potential to generate flawed data by selecting inappropriate

254 reference genes (Dheda et al. 2005; Svingen et al. 2014). Therefore, the suitability of employed

255 reference genes must be empirically verified for all individual experiments. This is further exemplified

256 by these tissue samples, where animals having been exposed to chemicals show altered expression of

257 constitutively expressed 'housekeeping' genes, both in tissues with obvious pathology, but also tissues

258 where no histopathological effects are discernible. But an additional aspect to consider in toxicological

259 studies is also the potential induction of widespread necrosis that could compromise the overall quality

260 of the RNA pool.

262 In terms of our data set, several of the analysed reference genes can be successfully employed for RT-

263 qPCR analysis. NormFinder suggests that both Hprt and Sdha are relatively stable across all the tissues

264 examined, including after chemical exposure. Other genes were scored as borderline suitable and

265 included Rps 18, Rpl13a and Ubc, but with Tbp, B2m, Gapdh and Rn18s not suitable. Contradictory, the

266 BestKeeper software suggested all genes except Pgkl and Actb to be stable enough for normalization

267 in the control tissues. A discrepancy in stability rankings and outcomes between different analytical

268 methods such as NormFinder and BestKeeper has been reported before and are attributed to the 
269 different theoretical algorithms that are employed (Andersen et al. 2004; Martínez-Beamonte et al.

270 2011; Pfaffl et al. 2004). Nevertheless, they are often in overall agreement, which was also the case

271 with our data with the exception of Gapdh and Rn18s in control tissues. For Rn18s, a p-value of 0.3

272 excludes the possibility of determining with certainty if it is stably expressed. But more importantly,

273 the NormFinder algorithm shows a bias towards a variant gene if several other genes display a

274 systematic variation across samples, which is likely the case for Rn $18 s$ in these tissues. Finally, a gene

275 does not have to rank on top of the list to be suitable for normalization purposes as long as they

276 perform better than the exclusion criteria. Further, it is recommended to use the geometric mean of two

277 or more reference genes rather than relying on a single gene.

279 Although screening all tissues under all experimental conditions when selecting suitable reference

280 genes is recommended, it is not always practically feasible. Therefore, we suggest a monitoring

281 protocol after initial screening of selected tissues, then re-screen when appropriate. Firstly, we reiterate

282 the importance of always normalising tissue samples at the RNA level; that is, using a stable input

283 amount of RNA for all cDNA synthesis reaction, as variation in reverse transcription protocols can

284 significantly affect downstream RT-qPCR assays (Ståhlberg et al. 2004; Bustin et al 2015). Secondly,

285 after selecting 2 or more reference genes that are deemed stable in the tissues to be examined, monitor

286 for any significant changes in $\mathrm{Ct}$ values. If $\mathrm{Ct}$ values change by more than 2 cycles between biological

287 replicates, selection of other reference genes should be considered; after additional screening tests if

288 necessary. Thirdly, to adjust for smaller changes in expression of the reference genes, the use of a

289 geometric mean from at least three reference genes to normalize data has been recommended

290 (Vandesompele et al. 2002). In this manner, significant changes to the expression of reference genes

291 following experimental conditions can be detected, ultimately avoiding reporting of significantly

292 flawed data. 


\section{ACKNOWLEDGMENTS}

We like to thank the staff at the animal facilities at the National Food Institute (Technical University of

Denmark) for husbandry and help with tissue collection.

298

299

300

301

302

303

304

305

306

307

308

309

310

311

312

313

314

315

316

317

318

319

320

321

322

323

324

325

326

327

\section{REFERENCES}

Andersen CL, Jensen JL, and Ørntoft TF. 2004. Normalization of real-time quantitative reverse transcription-PCR data: a model-based variance estimation approach to identify genes suited for normalization, applied to bladder and colon cancer data sets. Cancer Research 64:5245-5250.

Boberg J, Mandrup KR, Jacobsen PR, Isling LK, Hadrup N, Berthelsen L, Elleby A, Kiersgaard M, Vinggaard AM, Hass U, and Nellemann C. 2013. Endocrine disrupting effects in rats perinatally exposed to a dietary relevant mixture of phytoestrogens. Reproductive Toxicology 40:41-51.

Bustin S, Dhillon HS, Kirvell S, Greenwood C, Parker M, Shipley GL, Nolan T. 2015. Variability of the reverse transcription step: practical implications. Clinical Chemistry 61:202-212.

Cabiati M, Raucci S, Caselli C, Guzzardi MA, D'Amico A, Prescimone T, Giannessi D, and Del Ry S. 2012. Tissue-specific selection of stable reference genes for real-time PCR normalization in an obese rat model. Journal of Molecular Endocrinology 48:251-260.

Christiansen S, Kortenkamp A, Axelstad M, Boberg J, Scholze M, Jacobsen PR, Faust M, Lichtensteiger W, Schlumpf M, Burdorf A, and Hass U. 2012. Mixtures of endocrine disrupting contaminants modelled on human high end exposures: an exploratory study in rats. International Journal of Andrology 35:303-316.

Das RK, Banerjee S, and Shapiro BH. 2013. Extensive sex- and/or hormone-dependent expression of rat housekeeping genes. Endocrine Research 38:105-111. 
Dheda K, Huggett JF, Chang JS, Kim LU, Bustin SA, Johnson MA, Rook GA, and Zumla A. 2005. The implications of using an inappropriate reference gene for real-time reverse transcription PCR data normalization. Analytical Biochemistry 344:141-143.

DuBois B, Pearson J, Hastings B, Mahmood T, Chan T, Alnakhli A, and Cherala G. 2013. Maternal low-protein diet alters the expression of real-time quantitative polymerase chain reaction reference genes in an age-, sex-, and organ-dependent manner in rat offspring. Nutrition Research 33:235-241.

Hadrup N, Pedersen M, Skov K, Hansen NL, Berthelsen LO, Kongsbak K, Boberg J, Dybdahl M, Hass U, Frandsen H, and Vinggaard AM. 2015. Perfluorononaoic acid in combination with 14 chemicals exerts low dose mixture effects in rats. Archives of Toxicology In Press. (doi: 10.1007/s00204-015-1452-6)

Huggett J, Dheda K, Bustin S, and Zumla A. 2005. Real-time RT-PCR normalisation; strategies and considerations. Genes and Immunity 6:279-284.

Hvid H, Ekstrøm CT, Vienberg S, Oleksiewicz MB, and Klopfleisch R. 2011. Identification of stable and oestrus cycle-independent housekeeping genes in the rat mammary gland and other tissues. Veterinary Journal 190:103-108.

Kim I, Yang D, Tang X, and Carroll JL. 2011. Reference gene validation for qPCR in rat carotid body during postnatal development. BMC Research Notes 4:440.

Kozera B, and Rapacz M. 2013. Reference genes in real-time PCR. Journal of Applied Genetics 54:391-406.

Langnaese K, John R, Schweizer H, Ebmeyer U, and Keilhoff G. 2008. Selection of reference genes for quantitative real-time PCR in a rat asphyxial cardiac arrest model. BMC Molecular Biology 9:53.

Lardizábal MN, Nocito AL, Daniele SM, Ornella LA, Palatnik JF, and Veggi LM. 2012. Reference genes for real-time PCR quantification of microRNAs and messenger RNAs in rat models of hepatotoxicity. PLoS One 7:e36323.

Martínez-Beamonte R, Navarro MA, Larraga A, Strunk M, Barranquero C, Acín S, Guzman MA, Iñigo P, and Osada J. 2011. Selection of reference genes for gene expression studies in rats. Journal of Biotechnology 151:325-334.

Nair AR, Smeets K, Keunen E, Lee WK, Thévenod F, Van Kerkhove E, and Cuypers A. 2014. Renal cells exposed to cadmium in vitro and in vivo: normalizing gene expression data. Journal of Applied Toxicology In Press.

Nolan T, Hands RE, and Bustin SA. 2006. Quantification of mRNA using real-time RT-PCR. Nature Protocols 1:1559-1582.

O'Shaughnessy PJ, Monteiro A, and Fowler PA. 2011. Identification of stable endogenous reference genes for real-time PCR in the human fetal gonad using an external standard technique. Molecular Human Reproduction 17:620-625.

Pfaffl MW, Tichopad A, Prgomet C, and Neuvians TP. 2004. Determination of stable housekeeping genes, differentially regulated target genes and sample integrity: BestKeeper--Excel-based tool using pair-wise correlations. Biotechnology Letters 26:509-515.

Piller N, Decosterd I, and Sutler MR. 2013. Reverse transcription quantitative real-time polymerase chain reaction reference genes in the spared nerve injury model of neuropathic pain: validation and literature search. BMC Research Notes 6:266.

Pohjanvirta R, Niittynen M, Lindén J, Boutros PC, Moffat ID, and Okey AB. 2006. Evaluation of various housekeeping genes for their applicability for normalization of mRNA expression in dioxin-treated rats. Chemico-Biological Interactions 160:134-149. 
Ruedrich ED, Henzel MK, Hausman BS, and Bogie KM. 2013. Reference gene identification for reverse transcription-quantitative polymerase chain reaction analysis in an ischemic woundhealing model. Journal of Biomolecular Techniques 24:181-186.

Santin AP, Souza AF, Brum LS, and Furlanetto TW. 2013. Validation of reference genes for normalizing gene expression in real-time quantitative reverse transcription PCR in human thyroid cells in primary culture treated with progesterone and estradiol. Molecular Biotechnology 54:278-282.

Schmittgen TD, and Livak KJ. 2008. Analyzing real-time PCR data by the comparative C(T) method. Nature Protocols 3:1101-1108.

Silver N, Cotroneo E, Proctor G, Osailan S, Paterson KL, and Carpenter GH. 2008. Selection of housekeeping genes for gene expression studies in the adult rat submandibular gland under normal, inflamed, atrophic and regenerative states. BMC Molecular Biology 9:64.

Ståhlberg A, Hakansson J, Xian X, Semb H, Kubista M. 2004. Properties of the reverse transcription reaction in mRNA quantification. Clinical Chemistry 50:509-515.

Svingen T, Jørgensen A, and Rajpert-De Meyts E. 2014. Validation of endogenous normalizing genes for expression analyses in adult human testis and germ cell neoplasms. Molecular Human Reproduction 20:709-718.

Svingen T, Spiller CM, Kashimada K, Harley VR, and Koopman P. 2009. Identification of suitable normalizing genes for quantitative real-time RT-PCR analysis of gene expression in fetal mouse gonads. Sexual Development 3:194-204.

Swijsen A, Nelissen K, Janssen D, Rigo JM, and Hoogland G. 2012. Validation of reference genes for quantitative real-time PCR studies in the dentate gyrus after experimental febrile seizures. BMC Research Notes 5:685.

Taki FA, Abdel-Rahman AA, and Zhang B. 2014. A comprehensive approach to identify reliable reference gene candidates to investigate the link between alcoholism and endocrinology in Sprague-Dawley rats. PLoS One 9:e94311.

Vandesompele J, De Preter K, Pattyn F, Poppe B, Van Roy N, De Paepe A, and Speleman F. 2002. Accurate normalization of real-time quantitative RT-PCR data by geometric averaging of multiple internal control genes. Genome Biology 3:RESEARCHDD34.

Verma AS, and Shapiro BH. 2006. Sex-dependent expression of seven housekeeping genes in rat liver. Journal of Gastroenterology and Hepatology 21:1004-1008. 
441

442

443

444

445

446

447

448

449 
1

Box plot representation of RT-qPCR threshold $(\mathrm{Ct})$ values of 12 reference genes in rat tissues.

The reference genes were assayed across rat tissue cDNA samples, with each box plot representing the biological replicates. A) Box plot of 24 juvenile rat tissues; 4 each of liver, fat pad, adrenal, prostate, testis and ovary. B) Box plot of 16 adult rat tissues; 4 each of liver, fat pad, prostate and testis. Boxes denote median values with upper and lower quartiles, and whiskers minimum and maximum outliers.

A

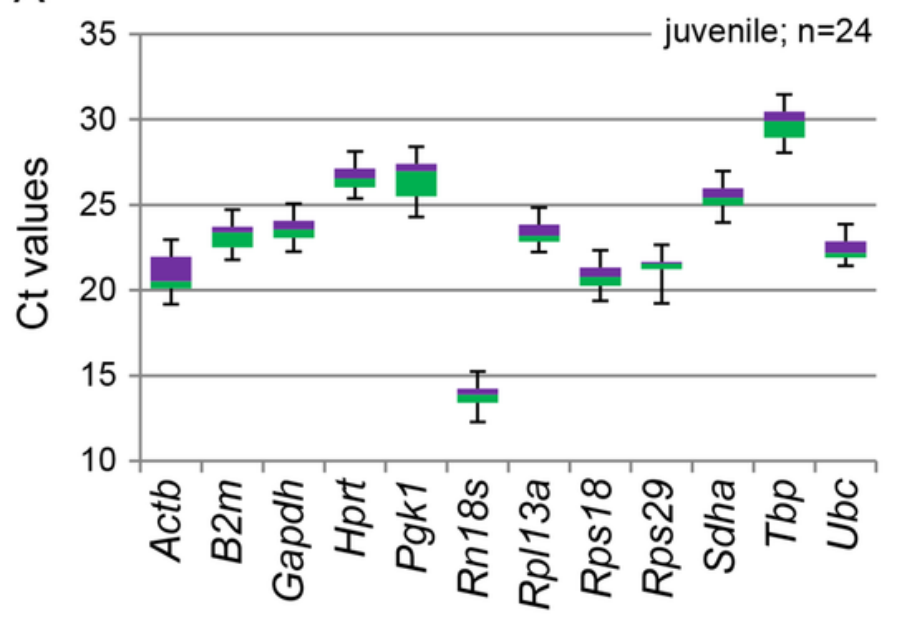

B

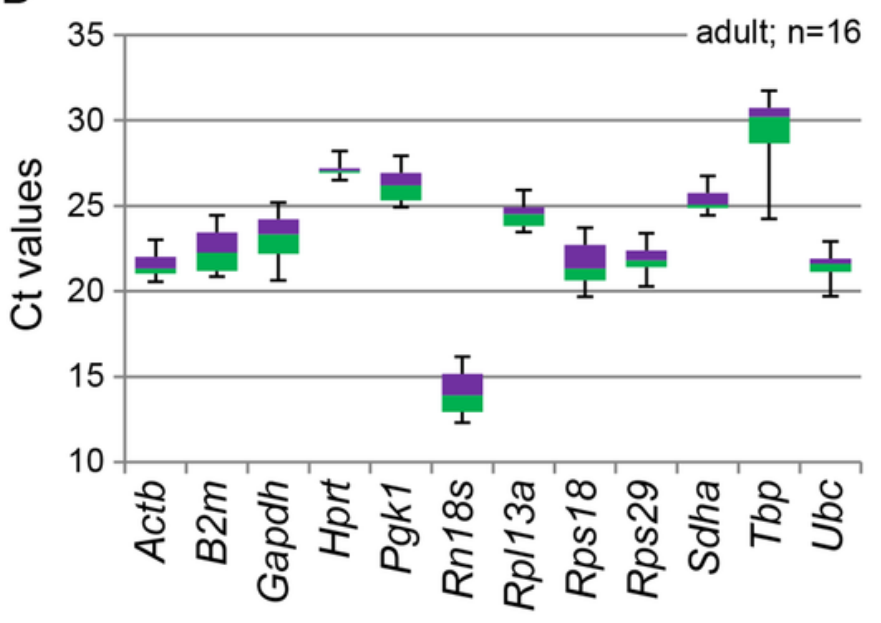


2

Relative expression stability (S) of 12 reference genes across rat tissues as determined by NormFinder.

The 12 reference genes were assayed across A) control tissues ( $n=40)$ from juvenile and adult rats and B) the control tissues plus adult tissues from rats subjected to chemical exposures $(n=76)$. The tissues included prostate, testis, adrenal, liver, fat, and ovary. Higher $\mathrm{S}$-values represent lower expression stability, with $\mathrm{S}<0.5$ typically indicating relative stability suitable for use as endogenous normalization. The data show a shift towards higher S-values (B vs. A) for the most unstable gene transcripts following chemical exposure.

A

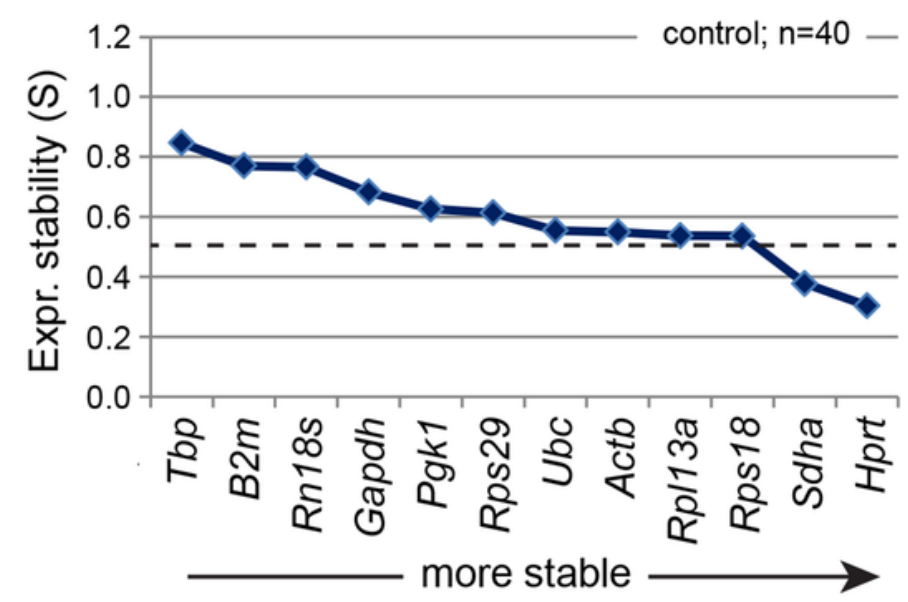

B

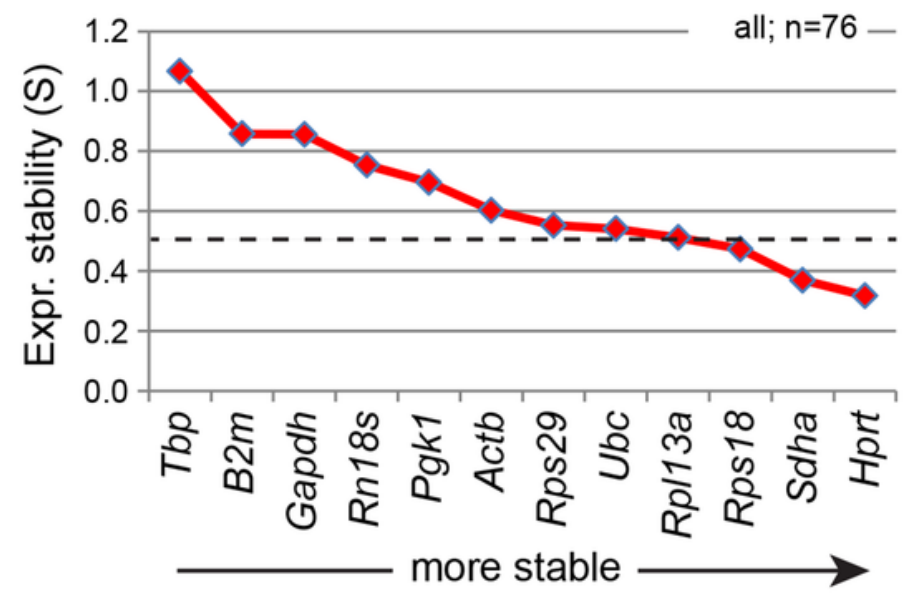




\section{Table $\mathbf{1}$ (on next page)}

List of putative rat reference genes and correspondingTaqMan assays. 


\section{Table 1:}

\begin{tabular}{|l|l|l|c|}
\hline Gene & RefSeq & Name & TaqMan assay \\
\hline$A c t b$ & NM_031144 & Beta actin & Rn00667869_m1 \\
\hline$B 2 m$ & NM_012512 & Beta-2 microglobulin & Rn00560865_m1 \\
\hline Gapdh & NM_017008 & Glyceraldehyde-3-phosphate dehydrogenase & Rn01775763_g1 \\
\hline$H p r t 1$ & NM_012583 & Hypoxanthine guanine phosphoribosyl transferase & Rn01527840_m1 \\
\hline$P g k 1$ & NM_053291 & Phosphoglycerate kinase 1 & Rn01474008_gH \\
\hline$R n 18 s$ & NR_046237 & 18S ribosomal RNA & $\begin{array}{c}\text { (Boberg et al. } \\
\text { 2013) }\end{array}$ \\
\hline$R p l 13 a$ & NM_173340 & Ribosomal protein L13A & Rn00821946_g1 \\
\hline$R p s 18$ & NM_213557 & Ribosomal protein S18 & Rn01428913_gH \\
\hline$R p s 29$ & NM_012876 & Ribosomal protein S29 & Rn00820645_g1 \\
\hline$S d h a$ & NM_130428 & $\begin{array}{l}\text { Succinate dehydrogenase complex, subunit A, } \\
\text { flavoprotein (Fp) }\end{array}$ & Rn00590475_m1 \\
\hline$T b p$ & NM_001004198 & TATA box binding protein & Rn01455646_m1 \\
\hline$U b c$ & NM_017314 & Ubiquitin C & Rn01789812_g1 \\
\hline
\end{tabular}


Table 2 (on next page)

Mean qRT-PCR threshold (Ct) values of 12 referencesgenes in juvenile (13-17 days post natal) rat tissues.

Mean \pm standard deviation

(SD) was calculated from 4 biological replicates $(n=4)$. 


\section{Table 2:}

3

\begin{tabular}{|l|c|c|c|c|c|c|c|}
\hline Gene & $\begin{array}{c}\text { Liver } \\
(\text { Mean } \pm \text { SD) }\end{array}$ & $\begin{array}{c}\text { Fat pad } \\
(\text { Mean } \pm \\
\text { SD) }\end{array}$ & $\begin{array}{c}\text { Adrenal } \\
(\text { Mean } \pm \\
\text { SD) }\end{array}$ & $\begin{array}{c}\text { Prostate } \\
(\text { Mean } \pm \\
\text { SD) }\end{array}$ & $\begin{array}{c}\text { Testis } \\
(\text { Mean } \pm \\
\text { SD) }\end{array}$ & $\begin{array}{c}\text { Ovary } \\
(\text { Mean } \pm \\
\text { SD) }\end{array}$ & $\begin{array}{c}\text { All } \\
\text { (Mean } \pm \\
\text { SD) }\end{array}$ \\
\hline $\boldsymbol{A c t b}$ & $23.0 \pm 0.23$ & $22.0 \pm 0.31$ & $20.5 \pm 0.31$ & $20.0 \pm 0.30$ & $19.7 \pm 0.69$ & $20.4 \pm 0.32$ & $20.9 \pm 1.25$ \\
\hline $\boldsymbol{B 2 m}$ & $23.6 \pm 0.21$ & $22.7 \pm 0.19$ & $22.1 \pm 0.32$ & $23.9 \pm 0.26$ & $23.9 \pm 0.60$ & $22.6 \pm 0.51$ & $23.2 \pm 0.80$ \\
\hline Gapdh & $24.1 \pm 0.19$ & $24.2 \pm 0.74$ & $22.7 \pm 0.52$ & $23.9 \pm 0.17$ & $23.2 \pm 0.32$ & $23.2 \pm 0.18$ & $23.6 \pm 0.69$ \\
\hline $\boldsymbol{H p r t}$ & $28.0 \pm 0.37$ & $27.1 \pm 0.16$ & $26.2 \pm 0.35$ & $26.7 \pm 0.24$ & $25.7 \pm 0.26$ & $26.0 \pm 0.26$ & $26.6 \pm 0.81$ \\
\hline $\boldsymbol{P g k 1}$ & $27.9 \pm 0.32$ & $26.4 \pm 0.57$ & $24.7 \pm 0.35$ & $27.3 \pm 0.39$ & $27.3 \pm 0.09$ & $25.5 \pm 0.21$ & $26.5 \pm 1.18$ \\
\hline $\boldsymbol{R n 1 8 s}$ & $13.8 \pm 0.45$ & $12.5 \pm 0.19$ & $13.9 \pm 0.33$ & $14.2 \pm 0.27$ & $13.9 \pm 0.65$ & $14.3 \pm 0.38$ & $13.8 \pm 0.69$ \\
\hline $\boldsymbol{R p l 1 3 a}$ & $25.4 \pm 0.17$ & $23.8 \pm 0.12$ & $23.2 \pm 0.18$ & $23.1 \pm 0.26$ & $22.9 \pm 0.06$ & $22.3 \pm 0.06$ & $23.5 \pm 1.02$ \\
\hline $\boldsymbol{R p s 1 8}$ & $22.3 \pm 0.33$ & $21.4 \pm 0.18$ & $20.8 \pm 0.11$ & $20.5 \pm 0.33$ & $20.5 \pm 0.24$ & $19.6 \pm 0.22$ & $20.9 \pm 0.88$ \\
\hline $\boldsymbol{R p s 2 9}$ & $21.6 \pm 0.24$ & $21.5 \pm 0.12$ & $21.9 \pm 0.12$ & $21.3 \pm 0.18$ & $21.2 \pm 0.76$ & $19.3 \pm 0.11$ & $21.1 \pm 0.91$ \\
\hline $\boldsymbol{S d h a}$ & $26.5 \pm 0.26$ & $25.6 \pm 0.19$ & $24.3 \pm 0.36$ & $26.0 \pm 0.21$ & $25.1 \pm 0.11$ & $25.1 \pm 0.38$ & $25.4 \pm 0.76$ \\
\hline $\boldsymbol{T b p}$ & $32.7 \pm 0.31$ & $29.8 \pm 0.23$ & $30.2 \pm 0.37$ & $30.1 \pm 0.31$ & $28.2 \pm 0.23$ & $28.9 \pm 0.13$ & $30.0 \pm 1.43$ \\
\hline $\boldsymbol{U b c}$ & $23.9 \pm 0.26$ & $23.0 \pm 0.26$ & $22.3 \pm 0.29$ & $21.7 \pm 0.16$ & $22.0 \pm 0.18$ & $22.0 \pm 0.14$ & $22.5 \pm 0.78$ \\
\hline
\end{tabular}

4

5

6 
Table 3 (on next page)

Mean RT-qPCR threshold (Ct) values of 12 referencegenes in adult rat tissues.

Mean \pm standard deviation

(SD) was calculated from 4 biological replicates $(n=4)$. 


\section{Table 3:}

\begin{tabular}{|l|c|c|c|c|c|}
\hline Gene & $\begin{array}{c}\text { Liver } \\
(\mathrm{Mean} \pm \mathrm{SD})\end{array}$ & $\begin{array}{c}\text { Fat pad } \\
(\mathrm{Mean} \pm \mathrm{SD})\end{array}$ & $\begin{array}{c}\text { Prostate } \\
(\mathrm{Mean} \pm \mathrm{SD})\end{array}$ & $\begin{array}{c}\text { Testis } \\
(\mathrm{Mean} \pm \mathrm{SD})\end{array}$ & $\begin{array}{c}\text { All } \\
(\mathrm{Mean} \pm \mathrm{SD})\end{array}$ \\
\hline $\boldsymbol{A c t b}$ & $23.1 \pm 0.16$ & $21.3 \pm 0.16$ & $21.1 \pm 0.49$ & $21.0 \pm 0.30$ & $21.6 \pm 0.92$ \\
\hline $\boldsymbol{B 2 m}$ & $21.4 \pm 0.38$ & $21.1 \pm 0.27$ & $23.9 \pm 0.81$ & $23.3 \pm 0.26$ & $22.4 \pm 1.33$ \\
\hline Gapdh & $20.7 \pm 0.12$ & $23.0 \pm 0.25$ & $24.6 \pm 0.25$ & $23.7 \pm 0.31$ & $23.0 \pm 1.48$ \\
\hline $\boldsymbol{H p r t}$ & $27.7 \pm 0.39$ & $27.1 \pm 0.11$ & $26.8 \pm 0.26$ & $27.0 \pm 0.17$ & $27.1 \pm 0.43$ \\
\hline $\boldsymbol{P g k 1}$ & $25.8 \pm 0.35$ & $25.2 \pm 0.18$ & $26.9 \pm 0.47$ & $26.9 \pm 0.32$ & $26.2 \pm 0.81$ \\
\hline $\boldsymbol{R n 1 8 s}$ & $14.8 \pm 1.55$ & $12.7 \pm 0.28$ & $14.7 \pm 0.94$ & $14.4 \pm 1.56$ & $14.1 \pm 1.38$ \\
\hline $\boldsymbol{R p l 1 3 a}$ & $25.6 \pm 0.35$ & $24.3 \pm 0.40$ & $23.6 \pm 0.16$ & $24.5 \pm 0.23$ & $24.5 \pm 0.79$ \\
\hline $\boldsymbol{R p s 1 8}$ & $23.1 \pm 0.82$ & $22.3 \pm 0.75$ & $21.0 \pm 0.27$ & $19.8 \pm 0.21$ & $21.5 \pm 1.38$ \\
\hline $\boldsymbol{R p s 2 9}$ & $23.2 \pm 0.25$ & $22.0 \pm 0.38$ & $21.1 \pm 0.68$ & $21.5 \pm 0.29$ & $22.0 \pm 0.90$ \\
\hline Sdha & $25.0 \pm 0.42$ & $24.7 \pm 0.19$ & $26.4 \pm 0.22$ & $25.2 \pm 0.20$ & $25.3 \pm 0.69$ \\
\hline Tbp & $31.6 \pm 0.61$ & $30.2 \pm 0.25$ & $30.3 \pm 0.25$ & $24.8 \pm 0.40$ & $29.2 \pm 2.73$ \\
\hline $\boldsymbol{U b c}$ & $22.1 \pm 0.42$ & $21.8 \pm 0.17$ & $21.5 \pm 0.16$ & $20.1 \pm 0.30$ & $21.4 \pm 0.84$ \\
\hline
\end{tabular}

3 
Table 4(on next page)

Mean RT-qPCR threshold ( $\mathrm{Ct}$ ) values of 12 reference genesin juvenile $(\mathrm{J})$ and adult $(\mathrm{A})$ tissues from rats exposed to Mix450.

Mean \pm standard

deviation (SD) was calculated from 4 biological

replicates $(n=4)$. 


\section{Table 4:}

\begin{tabular}{|l|c|c|c|}
\hline Gene & $\begin{array}{c}\text { Ovary (J) } \\
\text { +Mix450 } \\
\text { (Mean } \pm \text { SD) }\end{array}$ & $\begin{array}{c}\text { Prostate (J) } \\
\text { +Mix450 } \\
\text { (Mean } \pm \text { SD) }\end{array}$ & $\begin{array}{c}\text { Prostate (A) } \\
\text { +Mix450 } \\
\text { (Mean } \pm \text { SD) }\end{array}$ \\
\hline Actb & $20.6 \pm 0.45$ & $20.1 \pm 0.19$ & $21.4 \pm 0.12$ \\
\hline B2m & $23.0 \pm 0.47$ & $23.8 \pm 0.15$ & $24.4 \pm 0.29$ \\
\hline Gapdh & $23.2 \pm 0.10$ & $24.1 \pm 0.36$ & $24.2 \pm 0.19$ \\
\hline Hprt & $26.2 \pm 0.15$ & $26.6 \pm 0.15$ & $26.9 \pm 0.06$ \\
\hline Pgk1 & $25.6 \pm 0.28$ & $27.1 \pm 0.15$ & $26.5 \pm 0.07$ \\
\hline Rn18s & $14.1 \pm 0.16$ & $14.5 \pm 0.56$ & $14.8 \pm 0.12$ \\
\hline Rpl13a & $22.7 \pm 0.11$ & $22.8 \pm 0.26$ & $23.7 \pm 0.04$ \\
\hline Rps18 & $19.8 \pm 0.19$ & $20.1 \pm 0.31$ & $21.0 \pm 0.09$ \\
\hline Rps29 & $19.5 \pm 0.04$ & $21.2 \pm 0.25$ & $21.6 \pm 0.05$ \\
\hline Sdha & $25.1 \pm 0.28$ & $25.8 \pm 0.25$ & $26.3 \pm 0.16$ \\
\hline Tbp & $29.2 \pm 0.35$ & $29.8 \pm 0.19$ & $30.4 \pm 0.08$ \\
\hline Ubc & $22.4 \pm 0.22$ & $21.6 \pm 0.29$ & $21.3 \pm 0.06$ \\
\hline
\end{tabular}

3

4

5 
Table 5 (on next page)

Mean RT-qPCR threshold (Ct) values of 12 referencegenes in adult tissues from rats exposed to hPFNA or hPFNA/Mix.

Mean \pm standard deviation

(SD) was calculated from 4 biological replicates $(n=4)$. 


\section{Table 5:}

\begin{tabular}{|l|c|c|c|c|c|c|}
\hline Gene & $\begin{array}{c}\text { Liver } \\
\text { +hPFNA } \\
\text { (Mean } \pm \text { SD) }\end{array}$ & $\begin{array}{c}\text { Liver } \\
\text { +hPFNA/mix } \\
\text { (Mean } \pm \text { SD) }\end{array}$ & $\begin{array}{c}\text { Fat pad } \\
\text { +hPFNA } \\
\text { (Mean } \pm \text { SD) }\end{array}$ & $\begin{array}{c}\text { Fat pad } \\
\text { +hPFNA/mix } \\
\text { (Mean } \pm \text { SD) }\end{array}$ & $\begin{array}{c}\text { Testis } \\
\text { +hPFNA } \\
\text { (Mean } \pm \text { SD) }\end{array}$ & $\begin{array}{c}\text { Testis } \\
\text { +hPFNA/mix } \\
\text { (Mean } \pm \text { SD) }\end{array}$ \\
\hline Actb & $22.8 \pm 0.06$ & $22.5 \pm 0.37$ & $21.6 \pm 0.30$ & $21.6 \pm 0.34$ & $20.3 \pm 0.25$ & $20.7 \pm 0.29$ \\
\hline B2m & $21.4 \pm 0.12$ & $21.5 \pm 0.27$ & $20.8 \pm 0.15$ & $21.2 \pm 0.53$ & $23.6 \pm 0.47$ & $23.8 \pm 0.44$ \\
\hline Gapdh & $19.8 \pm 0.18$ & $19.7 \pm 0.16$ & $24.1 \pm 0.53$ & $23.5 \pm 0.72$ & $23.9 \pm 0.30$ & $22.2 \pm 1.34$ \\
\hline Hprt & $26.5 \pm 0.27$ & $26.4 \pm 0.17$ & $26.9 \pm 0.18$ & $26.7 \pm 0.81$ & $26.9 \pm 0.30$ & $27.2 \pm 0.24$ \\
\hline $\boldsymbol{P g k 1}$ & $24.3 \pm 0.24$ & $24.1 \pm 0.26$ & $25.6 \pm 0.34$ & $25.4 \pm 0.33$ & $27.3 \pm 0.45$ & $27.8 \pm 0.42$ \\
\hline $\boldsymbol{R n 1 8 s}$ & $15.1 \pm 1.27$ & $14.1 \pm 0.17$ & $12.6 \pm 0.27$ & $13.4 \pm 1.10$ & $12.2 \pm 0.04$ & $14.1 \pm 0.89$ \\
\hline $\boldsymbol{R p l 1 3 a}$ & $23.1 \pm 0.19$ & $23.0 \pm 0.33$ & $23.8 \pm 0.29$ & $23.8 \pm 0.31$ & $24.4 \pm 0.33$ & $24.5 \pm 0.21$ \\
\hline $\boldsymbol{R p s 1 8}$ & $20.2 \pm 0.21$ & $20.0 \pm 0.37$ & $21.4 \pm 0.33$ & $21.5 \pm 0.25$ & $19.7 \pm 0.26$ & $19.9 \pm 0.25$ \\
\hline $\boldsymbol{R p s 2 9}$ & $21.6 \pm 0.18$ & $21.5 \pm 0.28$ & $21.8 \pm 0.32$ & $21.8 \pm 0.23$ & $21.3 \pm 0.28$ & $21.5 \pm 0.22$ \\
\hline $\boldsymbol{S d h a}$ & $24.3 \pm 0.28$ & $24.1 \pm 0.21$ & $24.8 \pm 0.33$ & $24.6 \pm 0.53$ & $24.9 \pm 0.25$ & $25.0 \pm 0.31$ \\
\hline $\boldsymbol{T b p}$ & $30.5 \pm 0.41$ & $30.2 \pm 0.23$ & $29.8 \pm 0.14$ & $29.9 \pm 0.09$ & $24.3 \pm 0.33$ & $24.5 \pm 0.33$ \\
\hline Ubc & $21.0 \pm 0.21$ & $20.8 \pm 0.24$ & $21.8 \pm 0.08$ & $21.4 \pm 0.54$ & $19.8 \pm 0.39$ & $20.0 \pm 0.51$ \\
\hline
\end{tabular}


Table 6(on next page)

Expression stability between juvenile tissue typesaccording to relative NormFinder stability values.

Shaded boxes indicate a stability value $(S)>0.5$,

thus deemed unstable within the specific comparisons. 
2 Table 6:

\begin{tabular}{|c|c|c|c|c|c|c|}
\hline & $\begin{array}{c}\text { liver } \\
v s \\
\text { fat pad }\end{array}$ & $\begin{array}{c}\text { liver } \\
v s \\
\text { testis }\end{array}$ & $\begin{array}{c}\text { adrenal } \\
\text { vs } \\
\text { prostate }\end{array}$ & $\begin{array}{c}\text { prostate } \\
v s \\
\text { fat pad }\end{array}$ & $\begin{array}{c}\text { adrenal } \\
\text { vs } \\
\text { ovary }\end{array}$ & $\begin{array}{c}\text { ovary } \\
v s \\
\text { testis }\end{array}$ \\
\hline \multirow[t]{10}{*}{ Most stable } & $B 2 m$ & Sdha & Hprt & Rps29 & Hprt & Rpl13a \\
\hline & Sdha & Rps 18 & $R n 18 s$ & Hprt & $U b c$ & Gapdh \\
\hline & $A c t b$ & $U b c$ & Rpl13a & $T b p$ & $A c t b$ & $U b c$ \\
\hline & Rps 18 & Hprt & $T b p$ & Sdha & Rpl13a & Sdha \\
\hline & Hprt & Gapdh & Rps18 & Gapdh & $R n 18 s$ & Rps18 \\
\hline & $R n 18 s$ & Rpl13a & Gapdh & Rpl13a & Rps18 & Hprt \\
\hline & $U b c$ & Pgkl & $A c t b$ & Rps 18 & Gapdh & $T b p$ \\
\hline & Rpl13a & Rps29 & Rps29 & Pgkl & $B 2 m$ & $R n 18 s$ \\
\hline & Pgkl & $B 2 m$ & Sdha & $U b c$ & $T b p$ & $B 2 m$ \\
\hline & Rps29 & $A c t b$ & $U b c$ & $B 2 m$ & Pgk1 & $A c t b$ \\
\hline \multirow{2}{*}{ Least stable } & Gapdh & $R n 18 s$ & $B 2 m$ & $R n 18 s$ & Sdha & Pgkl \\
\hline & $T b p$ & $T b p$ & Pgkl & $A c t b$ & Rps29 & Rps29 \\
\hline
\end{tabular}

3

4 
Table 7 (on next page)

BestKeeper correlation analysis of 10 reference genesin rat tissues.

Control $=$ tissues from unexposed animals; All = tissues from unexposed and exposed animals. Shaded boxes indicate genes deemed unsuitable as reference genes based on too high SD or P values. 
3 Table 7:

\begin{tabular}{|c|c|c|c|c|c|c|c|c|c|}
\hline \multicolumn{5}{|c|}{ Control tissues; $n=40$} & \multicolumn{5}{|c|}{ All tissues; $n=76$} \\
\hline Gene & SD & $\mathrm{CV}$ & $r$ & $P$ & Gene & SD & $\mathrm{CV}$ & $r$ & $P$ \\
\hline$R n 18 s$ & 0.5438 & 3.9513 & -0.222 & 0.296 & Hprt & 0.4612 & 1.7226 & 0.747 & 0.001 \\
\hline Gapdh & 0.5597 & 2.3766 & 0.634 & 0.001 & Rps29 & 0.5647 & 2.6401 & 0.483 & 0.001 \\
\hline Sdha & 0.6169 & 2.4245 & 0.778 & 0.001 & Sdha & 0.6027 & 2.3911 & 0.679 & 0.001 \\
\hline$U b c$ & 0.6408 & 2.8510 & 0.797 & 0.001 & Rpl13a & 0.7404 & 3.1224 & 0.674 & 0.001 \\
\hline Hprt & 0.6792 & 2.5506 & 0.927 & 0.001 & $U b c$ & 0.7584 & 3.5106 & 0.501 & 0.001 \\
\hline Rps18 & 0.6827 & 3.2732 & 0.911 & 0.001 & Rps 18 & 0.8150 & 3.9201 & 0.747 & 0.001 \\
\hline Rps29 & 0.7000 & 3.3100 & 0.467 & 0.021 & $R n 18 s$ & 0.8260 & 5.9426 & 0.230 & 0.046 \\
\hline Rpl13a & 0.7822 & 3.3351 & 0.960 & 0.001 & $A c t b$ & 0.8794 & 4.1409 & 0.467 & 0.001 \\
\hline$P g k 1$ & 1.0420 & 3.9300 & 0.666 & 0.001 & Pgk1 & 1.0071 & 3.8459 & 0.476 & 0.001 \\
\hline$A c t b$ & 1.0472 & 5.0032 & 0.841 & 0.001 & Gapdh & 1.1385 & 4.9379 & 0.310 & 0.007 \\
\hline
\end{tabular}

4

5

6

7

8

9

10 